\title{
Effects of long-term low-glycaemic index starchy food on plasma glucose and lipid concentrations and adipose tissue cellularity in normal and diabetic rats
}

\author{
BY MURIEL LERER-METZGER ${ }^{1}$, SALWA W. RIZKALLA ${ }^{1}$, JING LUO ${ }^{1}$, \\ MARTINE CHAMP', MORVARID KABIR ${ }^{1}$, FRANCCOISE BRUZZO ${ }^{1}$, \\ FRANCIS BORNET ${ }^{1,3}$ AND GERARD SLAMA ${ }^{1 *}$ \\ 'Department of Diabetes, INSERM U341, Hôtel-Dieu Hospital, 75181 Paris Cedex 04, France \\ ${ }^{2}$ Laboratory of Nutrition, INRA, Nantes, France \\ ${ }^{3}$ Eridania Béghin, Say, Paris, France
}

(Received 28 March 1995 - Revised 26 July 1995 - Accepted 15 September 1995)

\begin{abstract}
The present study aimed to assess the metabolic consequences of the chronic ingestion of two starches giving different postprandial glycaemic responses in normal and diabetic rats. The two starches chosen were mung-bean (Phaseolus aureus) starch (97\% pure starch) and wheat starch presented as ground French toast. First, we studied the characteristics of these two starches. In vitro the $\alpha$-amylase (EC 3.2.1.1) digestibilities of these starches were 40 (SE 3) and 62 (SE 4) \% respectively at 30 min, whereas the contents of resistant starch were 77 (SE 4) and 22 (SE 4) g/kg respectively. In vivo the mungbean starch produced lower postprandial glycaemic responses than the wheat starch (areas under the curve were: 91 (SE 28) and 208 (SE 33) mmol. $\mathrm{min} / \mathrm{l}, P<0.05$ ) in normal rats $(n$ 8). We then submitted twenty-eight normal and twenty-eight diabetic (neonatal streptozotocin on second day of birth) male Sprague-Dawley rats (6 weeks old) to a diet containing $570 \mathrm{~g}$ starch/ $\mathrm{kg}$ as either mung-bean starch or wheat starch ( $n 14$ rats/group). After 5 weeks on the diets food intakes and body weights were identical in each group. Liver and kidney weights were comparable when expressed as relative weight. The mungbean-starch diet slightly decreased epididymal fat-pad weight $(P<0 \cdot 14$, ANOVA) and led to a marked decrease in adipocyte volume $(P<0.05)$. Plasma triacylglycerol and phospholipid concentrations were lower after the mung-bean-starch diet than after the wheat-starch diet in both normal and diabetic rats, whereas free fatty acid concentrations were lower only in normal rats. Similarly, non-fasting plasma glucose concentrations decreased $(P<0.05)$ in normal rats fed on mung-bean starch but not in diabetic ones $(P<0 \cdot 14)$. Insulin levels tended to be lower, but not significantly, after mung-bean-starch feeding than after wheat starch. We conclude that the replacement of $570 \mathrm{~g}$ wheat starch $/ \mathrm{kg}$ diet with mung-bean starch for 5 weeks resulted in (1) lowered non-fasting plasma glucose and free fatty acid levels in normal but not in diabetic rats, (2) a reduction in plasma triacylglycerol concentration and adipocyte volume in both normal and diabetic rats. Thus, the type of starch mixed into the diet may have important metabolic consequences in normal and diabetic rats.
\end{abstract}

Starch: Glycaemic index: Adipose tissue: Diabetes

Different foods may produce markedly different blood glucose responses independent of the amount of carbohydrate they contain. Crapo et al. (1977) demonstrated this phenomenon in normal and diabetic subjects. They found that the postprandial glucose and insulin responses to $50 \mathrm{~g}$ carbohydrate as cooked potato or pure glucose were much

* For reprints. 
higher than those to an equivalent load in the form of maize or rice. Jenkins et al. (1981) then introduced the glycaemic index concept, allowing the classification of carbohydrates according to the glycaemic and insulinaemic responses they induce after a test meal (Jenkins et al. 1981; Wolever et al. 1991). However, few clinical studies have undertaken the assessment of the short-term metabolic effects of low glycaemic-index diets, in either hyperlipidaemic or diabetic patients (Jenkins et al. $1987 a, b$; Fontvieille et al. 1988a). In two recent studies the authors investigated the chronic effects of such diets in man (Brand et al. 1991; Fontvieille et al. 1992). The results suggest that low-glycaemic-index diets can be credited with two kinds of beneficial metabolic effects: lowering the plasma lipid levels, and contributing to better glycaemic control. However, these results are scarce, deal with heterogeneous populations (type 1 and type 2 diabetics, hyperlipidaemics) and vary in diet duration, type of ingested carbohydrate and total energy intake. Since type 2 diabetic patients often suffer from both hyperlipidaemia and abnormal glycaemic control, it would be of interest to evaluate whether they would benefit from a long-term low-glycaemic index diet. In addition, this type of diet may prove useful in normal subjects: the repeated low glycaemic and insulinaemic responses might result in a shift to a less diabetogenic or atherogenic plasma profile. Given the difficulty of conducting such a study in man, we decided to use an animal model. The aim of the present study, therefore, was to assess in normal and diabetic rats the chronic metabolic effects of two different starch-rich diets. The starches used were cooked mung-bean (Phaseolus aureus) starch in the form of Chinese noodles and wheat starch in the form of French toast, since we have demonstrated in our laboratory that the mung-bean starch has a very low glycaemic index: 67 (SE 5) \% (Bornet et al. 1989, M. Kabir, S. W. Rizkalla, J. Luo and G. Slama, unpublished results), whereas the French toast gives a high glycaemic index of 99 (SE 21) \% (Fontvieille et al. 1988 b). We investigated the consequences of these two starches, incorporated in mixed diets, on plasma glucose and lipid concentrations as well as epididymal adipose tissue cellularity.

\section{MATERIALS AND METHODS}

\section{Characterization of starches}

A first set of experiments was designed to characterize the two diets we intended to use: the mung-bean starch (cooked Chinese noodles, Pagoda Brand ${ }^{\circledR}$, manufactured in the Republic of China and purchased from local Asian supermarkets in Paris, France) and the French toast (Heudebert ${ }^{\circledR}$, Athis Mons, France) made with wheat flour.

In vitro $\alpha$-amylase digestibility. The two starches were tested in vitro to investigate their susceptibility to $\alpha$-amylase (EC 3.2.1.1), since it has been shown that the percentage of starch hydrolysed in vitro within $30 \mathrm{~min}$ is strongly correlated to the glycaemic index of starch in man (Bornet et al. 1989). A sample (18 g) of each of these starches was submitted, after 1 min sieving, to $\alpha$-amylase (Merck, Darmstadt, Germany) hydrolysis with 3000 units of porcine pancreatic $\alpha$-amylase $(166 \mathrm{U} / \mathrm{g}$ dry material) under constant stirring (30 rev. $/ \mathrm{min})$ in $200 \mathrm{ml}$ phosphate buffer $(0.005 \mathrm{M}, \mathrm{pH} 7)$ for $3 \mathrm{~h}$ at $37^{\circ}$. Every $5 \mathrm{~min}$ a $0.9 \mathrm{ml}$ sample was mixed with $4.5 \mathrm{ml}$ ethanol $(800 \mathrm{ml} / \mathrm{l})$ and acetic acid $(15 \mathrm{ml} / \mathrm{l})$ and stored overnight at $4^{\circ}$ (Leclère et al. 1993). Samples were then centrifuged at $9000 \mathrm{~g}$ for $10 \mathrm{~min}$. The soluble polysaccharides were thereafter assayed in the supernatant fraction using a sulphuric orcinol automatic method (Tollier \& Robin, 1979). Intra-assay reproducibility was $15 \%$ at $30 \mathrm{~min}$ and $4 \%$ at $180 \mathrm{~min}$.

Measurements of resistant starch. Resistant starch is the fraction of starch that escapes digestion and hydrolysis after incubation with $\alpha$-amylase. It was measured by the method of Englyst et al. (1992) and the modified Berry method (Champ, 1992). After amylase 
treatment and alcohol washing, $5 \mathrm{ml}$ water was added to the residue. Samples were mixed, incubated for $30 \mathrm{~min}$ at $100^{\circ}$ and then cooled in ice water and $5 \mathrm{ml} 4 \mathrm{M}-\mathrm{KOH}$ was added to disperse the resistant starch. After $30 \mathrm{~min}$ under magnetic stirring $1 \mathrm{ml}$ was added to

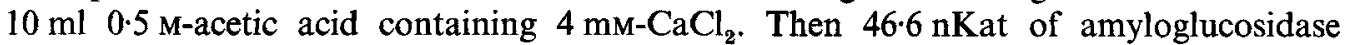
(400 AGU, EC 3.2.1.3, Novo Nordisk Bioindustries, Boulogne-Billancourt, France) was added, and the samples were incubated for $30 \mathrm{~min}$ at $70^{\circ}$. After neutralization and centrifugation, released glucose was determined by the glucose oxidase ( $E C$ 1.1.3.4) method (glucose GOD-PAP, Boehringer Mannheim, Germany) on an automatic analyser.

Postprandial glycaemic and insulinaemic responses. Test-meal experiments were performed for both types of starch. Twenty non-diabetic male Sprague-Dawley rats (body weight: 300 g, Centre d'Elevage Janvier, Le Genest St-Isle, France) were used. Approval to use laboratory animals was given by the French Ministry of Agriculture. Rats were placed in individual polypropylene cages for sedentary animals and maintained at $24^{\circ}$ with a $12 \mathrm{~h}$ light-dark cycle. Then they were trained for 2 weeks as follows: each morning a small amount of a powdered standard diet containing $(\mathrm{g} / \mathrm{kg})$ carbohydrates 575 , lipid 55 , and protein 225 as casein (semi-purified diet no. 210, Usine d'Alimentation Rationnelle, Villemoisson-sur-Orge, France) was introduced into the cage and removed after 15 min, whether the animals ate or not. Rats had free access to diet at 14.00 hours until 20.00 hours when they were left fasting overnight. By the end of the training period, rats were accustomed to eating a given amount of feed within $15 \mathrm{~min}$. After 2 weeks, two test-meal studies were performed with the two starches. After an overnight fast, at 08.00 hours, half of the rats $(n 10)$ received mung-bean starch ( $2 \mathrm{~g}$ dried material was cooked in boiling water for $4 \mathrm{~min}$ ), while the other half $(n 10)$ received $2 \mathrm{~g}$ wheat starch (ground French toast). Most of the rats ate the whole amount within $15 \mathrm{~min}$. Pentobarbital anaesthesia was then performed only on rats that consumed all the offered quantity. Blood samples were taken from the tip of the tail after $30,45,60,90$ and $150 \mathrm{~min}$, to measure plasma glucose and insulin levels. Fasting plasma glucose and insulin levels $(0 \mathrm{~min})$ had been previously determined for each rat under similar conditions.

\section{Chronic study}

Animals and diets. Twenty-eight normal and twenty-eight diabetic male Sprague-Dawley rats were used. Diabetes was induced by injecting rats on the second day of life with $100 \mathrm{mg} / \mathrm{kg}$ streptozotocin (Zanosar R, Upjohn, La Défense, France) in 0.005 M-citrate buffer ( $\mathrm{pH} \mathrm{4.5),} \mathrm{according} \mathrm{to} \mathrm{the} \mathrm{method} \mathrm{described} \mathrm{by} \mathrm{Portha} \mathrm{et} \mathrm{al.} \mathrm{(1989)} \mathrm{and} \mathrm{Bonner-Weir}$ et al. (1981). Normal rats were injected with an equivalent volume of vehicle buffer. At 6 weeks of age an intraperitoneal glucose tolerance test was performed to verify the presence of diabetes in rats receiving streptozotocin.

At 6 weeks of age both normal and diabetic rats (body weight: 155 (SE 2) v. 140 (SE 3) g, normal $v$. diabetic, ANOVA: $P<0.0001)$ were randomly ascribed for 5 weeks to diets containing $570 \mathrm{~g}$ starch $/ \mathrm{kg}$ as either mung-bean starch (cooked Chinese noodles) or wheat starch.

The mung-bean noodles were cooked in our laboratory every other day. We verified, by weighing the noodles before and after cooking and total desiccation, that the amount of starch lost in the cooking water was only $0 \cdot 17 \%$.

Cooked noodles and ground French toast were incorporated, using a mixer, into the powdered diet containing the fat, protein, cellulose, vitamins and mineral components prepared by UAR (Usine d'Alimentation Rationnelle, Villemoisson-sur-Orge, France). The other constitutents of the mung-bean-starch diet were as follows $(\mathrm{g} / \mathrm{kg}):$ fat 70 (maize oil 13, peanut oil 14 and suet 43), protein 230 as casein, cellulose 50 and mineral 
components plus vitamins 80 . The diet with the French toast was adjusted to contain $570 \mathrm{~g}$ pure wheat starch $/ \mathrm{kg}$, since the French toast contained $770 \mathrm{~g}$ wheat $\mathrm{starch} / \mathrm{kg}$. Consequently, there was a slight modification in the fat $(82 \mathrm{~g} / \mathrm{kg})$ and the protein $(218 \mathrm{~g} / \mathrm{kg})$ contents of the wheat-starch diet. The other constituents were the same. Thus, throughout the present study the mung-bean starch and the wheat starch were presented in the cooked and not the raw form.

Daily feed intake was determined and rats were weighed at the beginning of the dietary period and at the end of each week.

Before the end of the 5-week nutritional period a second intraperitoneal glucose tolerance test was performed under pentobarbital anaesthesia. At $2 \mathrm{~d}$ later, rats were decapitated between 08.30 and 09.30 hours, blood was collected and plasma was stored at $-20^{\circ}$ for further plasma glucose, insulin and lipid measurements. Epididymal fat pads, liver and kidneys were immediately removed and weighed.

Glucose tolerance tests. On the morning of the experiment, feed was removed at 08.00 hours. At 14.00 hours a glucose challenge was given intraperitoneally ( 2 g glucose $/ \mathrm{kg}$ body weight), under pentobarbital anaesthesia $(0.5 \mathrm{ml} / \mathrm{kg}$ body weight), and blood samples were taken at $0,15,30$ and $50 \mathrm{~min}$ from the tips of the rats' tails.

Preparation of isolated adipocytes. Epididymal adipocytes were prepared and isolated according to the method described by Rodbell (1964). Minced epididymal fat pads were incubated under slow agitation for $60 \mathrm{~min}$ at $37^{\circ}$ with collagenase (EC 3.4 24.3 Type II, Sigma, St. Louis, MO, USA) in Krebs-Ringer bicarbonate (KRBA) buffer, pH 7.4, containing $35 \mathrm{~g} / \mathrm{l}$ bovine albumin (Sigma RIA grade). Adipocytes were then filtered through a $250 \mu \mathrm{m}$ nylon screen, washed three times in the same buffer, and diluted in different proportions according to the study intended, in order to achieve approximate respective concentrations of $10^{6}$ and $4 \times 10^{5} \mathrm{cells} / \mathrm{ml}$ ). Two portions were removed for measurement of total lipid content, following the technique described by Dole \& Meinertz (1960), in order to determine the adipocyte number in each experiment.

Assessment of adipocyte volume and diameter. Portions of adipocyte suspension were photographed under a light microscope. Adipocyte volume was measured by a semiautomatic method, as described by Lavau et al. (1977). Mean cell diameter and volume were calculated using the formula advised by Goldrick (1967). The number of adipocytes was thus calculated after measurement of the total lipid content of the fat pads.

\section{Measurement of plasma variables}

Plasma glucose was measured by the glucose oxidase technique using a Beckman glucose analyser (Fullerton, CA, USA). Plasma insulin was determined by a radio-immunological method (CIS Bio International kit, Gif sur Yvette, France), fructosamine by spectrophotometry (Fructoamine test Plus adapted for Hitashi, Roche, Neuilly-sur-Seine, France). Plasma triacylglycerols (Biomérieux, Marcy l'Etoile, France), cholesterol (Labintest, Aixen-provence, France), phospholipids (Biomérieux) and free fatty acids (Biolyon, Dardilly, France) were also measured.

\section{Statistical analysis}

Overall comparisons among the four subgroups were done by using two-way ANOVA to test effects of diets, diabetes and their interactions. In the presence of an interaction (free fatty acid concentrations) or when the variances associated with each experimental mean were heterogeneous (plasma glucose), the difference between the dietary groups was tested in either diabetic or normal rats separately by one-way ANOVA. When the $F$ test was significant, differences between all pairs of means were tested using Fisher's least significant difference procedure and the Scheffé test. In these cases the comparison between diabetic 
and normal rats was carried out also using one-way ANOVA. The homogeneity of variances was verified. Student's $t$ test for unpaired data was used to compare the areas under plasma glucose and insulin curves after the test meals to characterize starches. All analyses were carried out with the Statview 512+ software program (Brainpower Inc, Calabasas, CA, USA). Results are given as means with their standard errors. Differences were considered significant when $P<0.05$.

\section{RESULTS \\ Characterization of starches (Table I)}

In vitro $\alpha$-amylase digestibility. Table 1 shows that the in-vitro digestibility measured within 30 min was higher for wheat starch than for mung-bean starch.

Measurements of resistant starch. The content of resistant starch was slightly higher in the mung-bean noodles than in the French toast.

Postprandial glycaemic and insulinaemic responses. As shown in Table 1, the areas under the plasma glucose and insulin curves were lower in rats that received the mung-bean starch than in those that received the wheat starch.

\section{Chronic study}

Feed intake, body and organ weights (Table 2). Both the mung-bean-starch and wheat-starch diets were well tolerated. Feed intake was comparable in normal and diabetic rats during the whole diet period, as shown in Table 2. Since cooking the mung-bean noodles made them hydrated and voluminous, the quantity of consumed feed was adjusted according to its dry-matter content. Feed intake was higher in rats (normal and diabetic) fed on the mung-bean starch during the second and third weeks, but this difference decreased with time, and feed intake was comparable for both diets at the end of the nutritional period.

Body weight was significantly lower in rats (normal and diabetic) fed on the mung-beanstarch diet until the fourth week (ANOVA: $P<0.05$ ). However, body weight was comparable for both diets at the end of the 5-week period.

Absolute liver, kidney and epididymal-fat-pad weights were higher in rats consuming the wheat-starch diet. However, these differences disappeared when they were expresed on a body-weight basis.

Cellularity of adipose tissue (Table 2). As shown in Table 2, diabetic rats had fewer epididymal adipocytes than normal rats $(P<0.001)$, and their adipocytes were smaller $(P$ $<0.05$ ).

The type of diet also affected the size of adipocytes: rats fed on the mung-bean-starch diet had smaller adipocytes than those fed on the wheat-starch diet $(P<0.01)$.

Intraperitoneal glucose tolerance tests. Plasma glucose responses were significantly higher in rats that received streptozotocin than in normal rats, both before and after the nutritional period ( $P<0.001$, results not shown). After 5 weeks of either the mung-beanstarch or the wheat-starch diet, however, rats produced comparable plasma glucose responses to an intraperitoneal glucose challenge.

Plasma variables (Table 3). At the end of the nutritional period the diabetic rats were hyperglycaemic $(P<0.01)$ and hypoinsulinaemic $(P<0.01)$ with high fructosamine levels when compared with the non-diabetic rats.

Normal rats fed on mung-bean starch showed low plasma glucose concentrations $(P<$ $0 \cdot 05$ ). Diabetic rats, however, had only a tendency to have low plasma glucose levels after the mung-bean-starch diet $(P<0 \cdot 14)$. Because of heterogeneous variances in plasma glucose between diabetic and normal rats, the results were analysed by one-way ANOVA 
Table 1. Characteristics of the two starches used in the present study

\begin{tabular}{|c|c|c|c|c|}
\hline \multirow[t]{2}{*}{ Type of starch... } & \multicolumn{2}{|c|}{ Mung bean (Phaseolus aureus) } & \multicolumn{2}{|c|}{ Wheat flour } \\
\hline & Mean & SE & Mean & SE \\
\hline Amylose $\dagger(\mathrm{g} / \mathrm{kg})$ & 320 & - & 270 & - \\
\hline Extent of in vitro hydrolysis $(30 \mathrm{~min})(\%)$ & 40 & 3 & 62 & 4 \\
\hline Resistant starch $(\mathrm{g} / \mathrm{kg})$ & 77 & 4 & 22 & 4 \\
\hline Glucose area under the curvef (mmol. $\mathrm{min} / \mathrm{l})$ & 91 & 28 & $208^{*}$ & 33 \\
\hline Insulin area under the curvet $(\mathrm{mU} \cdot \mathrm{min} / \mathrm{ml})$ & $2 \cdot 6$ & $0 \cdot 4$ & $6 \cdot 1$ & 3.9 \\
\hline
\end{tabular}

* Mean value was significantly different from that for mung-bean starch, $P<0.05$.

$\dagger$ Values from a previous study (Bornet et al. 1989; Fontvieille et al. 1988b).

$\ddagger$ Mean values for six rats per dietary group. For details of procedures, see pp. 724-725.

Table 2. Characteristics of normal and diabetic rats fed for 5 weeks on diets containing $570 \mathrm{~g}$ starch $/ \mathrm{kg}$ as mung-bean (Phaseolus aureus) starch or wheat starch*

(Mean values with their standard errors for fourteen rats per group)

\begin{tabular}{|c|c|c|c|c|c|c|c|c|c|c|}
\hline \multirow{3}{*}{$\begin{array}{l}\text { Rat type... } \\
\text { Starch type... }\end{array}$} & \multicolumn{4}{|c|}{ Normal } & \multicolumn{4}{|c|}{ Diabetic } & \multirow{2}{*}{\multicolumn{2}{|c|}{$\begin{array}{l}\text { Statistical } \\
\text { significance of } \\
\text { effect of : } \dagger\end{array}$}} \\
\hline & \multicolumn{2}{|c|}{ Mung bean } & \multicolumn{2}{|c|}{ Wheat } & \multicolumn{2}{|c|}{ Mung bean } & \multicolumn{2}{|c|}{ Wheat } & & \\
\hline & Mean & SE & Mean & $\mathbf{S E}$ & Mean & SE & Mean & $\mathbf{S E}$ & Diet & Diabetes \\
\hline Body weight & 5 & 4 & 376 & 9 & 316 & 8 & 326 & 18 & NS & $P<0.01$ \\
\hline $\begin{array}{l}\text { Total weight gain } \\
\text { (g/5 weeks per rat) }\end{array}$ & 199 & 5 & 2 & 7 & 3 & 8 & 190 & 17 & $P<0.05$ & $P<0.01$ \\
\hline $\begin{array}{l}\text { Total feed intake } \\
\text { (g/5 weeks per rat) }\end{array}$ & 3319 & 64 & 3274 & 59 & 3315 & 46 & 3355 & 118 & NS & NS \\
\hline $\begin{array}{l}\text { Feed intake index } f \\
(\mathrm{~g} / 418.4 \mathrm{~kJ})\end{array}$ & 6.0 & 0.2 & 7.0 & 0.2 & $5 \cdot 0$ & 0.2 & $6 \cdot 0$ & $1 \cdot 0$ & $P<0.05$ & $P<0.05$ \\
\hline Liver weight (g) & $12 \cdot 2$ & 0.2 & $13 \cdot 4$ & 0.4 & $12 \cdot 5$ & 0.4 & $13 \cdot 6$ & 0.9 & $P<0.05$ & NS \\
\hline $\begin{array}{l}\text { Relative liver weight } \\
(\mathrm{g} / \mathrm{kg})\end{array}$ & 34 & 1 & 35 & 1 & 39 & 1 & 41 & 1 & $P=0.15$ & $P<0.01$ \\
\hline Kidney weight (g) & $2 \cdot 4$ & 0.1 & $2 \cdot 7$ & $0-1$ & $2 \cdot 4$ & 0.1 & 26 & 0.2 & $P<0.05$ & NS \\
\hline $\begin{array}{l}\text { Relative kidney } \\
\text { weight }(\mathrm{g} / \mathrm{kg})\end{array}$ & 7 & 1 & 7 & 1 & 8 & 1 & 8 & 1 & NS & $P<0.01$ \\
\hline $\begin{array}{l}\text { Epididymal fat pad } \\
\text { weight }(\mathrm{g})\end{array}$ & $3 \cdot 3$ & $0 \cdot 2$ & 40 & $0 \cdot 2$ & $2 \cdot 0$ & $0 \cdot 2$ & $2 \cdot 3$ & 0.4 & $P=0.08$ & $P<0.001$ \\
\hline $\begin{array}{l}\text { Relative epididymal } \\
\text { fat pad weight }(\mathrm{g} / \mathrm{kg})\end{array}$ & 9 & 1 & 11 & 1 & 6 & 1 & 7 & 1 & NS & $P<0.001$ \\
\hline $\begin{array}{l}\text { Number of adipocytes } \\
\text { (cell } \times 10^{6} / \text { rat) }\end{array}$ & 33 & 3 & 26 & 1 & 23 & 2 & 19 & 2 & $P<0.05$ & $P<0.001$ \\
\hline Adipocyte volume $(\mathrm{pl})$ & 121 & 8 & 169 & 12 & 104 & 7 & 127 & 19 & $P<0.01$ & $P<0.02$ \\
\hline
\end{tabular}

* For details of diets and procedures, see pp. 724-726.

$\dagger$ ANOVA.

$\$$ Body-weight gain $/ 418.4 \mathrm{~kJ}$ (100 kcal) feed intake.

in each group. Plasma insulin levels were low in rats fed on mung-bean starch. However, no significant difference could be detected. Fructosamine levels were comparable with the two diets. Plasma triacylglycerol and phospholipid concentrations were decreased after the mung-bean-starch diet in both normal and diabetic rats. Plasma free fatty acids were also decreased by the same diet but only in normal rats $(P<0.05)$. 
Table 3. Non-fasting plasma variables in normal and diabetic rats fed for 5 weeks on diets containing $570 \mathrm{~g}$ starch $/ \mathrm{kg}$ as mung-bean (Phaseolus aureus) starch or wheat starch*

(Mean values with their standard errors for fourteen rats per group)

\begin{tabular}{|c|c|c|c|c|c|c|c|c|c|c|}
\hline \multirow{3}{*}{$\begin{array}{l}\text { Rat type... } \\
\text { Starch type... }\end{array}$} & \multicolumn{4}{|c|}{ Normal } & \multicolumn{4}{|c|}{ Diabetic } & \multirow{2}{*}{\multicolumn{2}{|c|}{$\begin{array}{l}\text { Statistical } \\
\text { significance of } \\
\text { effect of: } \dagger\end{array}$}} \\
\hline & \multicolumn{2}{|c|}{ Mung bean } & \multicolumn{2}{|c|}{ Wheat } & \multicolumn{2}{|c|}{ Mung bean } & \multicolumn{2}{|c|}{ Wheat } & & \\
\hline & Mean & SE & Mean & SE & Mean & $\mathbf{S E}$ & Mean & SE & Diet & Diabetes \\
\hline $\begin{array}{l}\text { Triacylglycerols } \\
(\mathrm{mmol} / \mathrm{l})\end{array}$ & $2 \cdot 24$ & $0 \cdot 13$ & $2 \cdot 61$ & $0 \cdot 24$ & $2 \cdot 26$ & 0.51 & $3 \cdot 31$ & $0 \cdot 18$ & $P<0.05$ & NS \\
\hline Cholesterol (mmol/l) & $2 \cdot 27$ & 0.05 & $2 \cdot 27$ & 0.07 & $2 \cdot 27$ & $0-05$ & $2 \cdot 45$ & 0.10 & NS & NS \\
\hline $\begin{array}{l}\text { Phospholipids } \\
(\mathrm{mmol} / \mathrm{l})\end{array}$ & 1.81 & $0 \cdot 03$ & 1.87 & 0.08 & 1.86 & 0.04 & $2 \cdot 16$ & $0 \cdot 13$ & $P<0.05$ & $P<0.05$ \\
\hline $\begin{array}{l}\text { Free fatty acids } \\
(\mathrm{mmol} / \mathrm{l})\end{array}$ & $0 \cdot 43$ & 0.02 & 0.62 & 0.07 & 0.42 & $0-03$ & $0 \cdot 39$ & 0.02 & $P<0.05$ & $P<0.05$ \\
\hline Fructosamine $(\mu \mathrm{mol} / 1)$ & 126 & 1 & 147 & 14 & 163 & 8 & 164 & 16 & NS & $P<0.05$ \\
\hline Insulin $(\mu \mathrm{U} / \mathrm{ml})$ & 219 & 31 & 288 & 51 & 140 & 17 & 168 & 28 & NS & $P<0.01$ \\
\hline Glucose (mmol/l) & $7 \cdot 7$ & $0 \cdot 1$ & $8 \cdot 1$ & 0.2 & $10 \cdot 5$ & 1.4 & $15 \cdot 0$ & $2 \cdot 7$ & $P<0.05$ & $P<0.01$ \\
\hline
\end{tabular}

* For details of diets and procedures, see pp. 724-727.

† Statistical significance was assessed by two-way ANOVA followed by Fisher's least significant difference test except for plasma glucose where the variances were heterogeneous, and plasma free fatty acids where there was an interaction between diabetes and diet effects. In these cases one-way ANOVA was used; the effect of diet was found only in normal rats.

\section{DISCUSSION}

The present study is the first to show that the mere replacement of a high-glycaemic-index starch by a low-glycaemic-index starch can lead to decreased adipocyte size and plasma lipid levels (triacylglycerols and phospholipids) in both normal and diabetic rats. Plasma glucose concentrations were also decreased but only in normal rats.

There was no relevant information in the literature about the effects of different starches on adipocytes. The smaller adipocyte size in rats fed on the low-glycaemic-index diet could be explained by one or more of the following mechanisms: a decrease in adipocyte lipogenesis or a modification in lipolysis (stimulated or inhibited). The insulin-stimulated glucose incorporation into total lipids was measured in the present study (results not shown) and we could not detect any significantly decreased responses in these nonresponsive cells from relatively old rats fed on mung-bean starch for 5 weeks. In a similar recent study, however, in younger rats after shorter periods of diet ( 3 weeks), small adipocytes from somewhat thin rats showed lower capacity to incorporate glucose into total lipids (M. Kabir, S. W. Rizkalla and G. Slama, unpublished results). Thus decreased lipogenesis in adipocytes of mung-bean-fed rats could be implicated in the observed decreased cell size. Lipolysis, however, was not studied in the present work.

Concerning plasma lipids, one study conducted in diabetic patients in our laboratory (Fontvieille et al. 1992) showed similar results to our present study in rats. The authors found that a 5-week low-glycaemic-index diet, followed by eighteen type 1 and type 2 diabetic patients, reduced plasma triacylglycerol and fructosamine, but not cholesterol or fasting glucose levels. After a shorter period, however, Wolever et al. (1992) found, in fifteen type 2 diabetic patients, that a 2 -week low-glycaemic-index diet decreased plasma cholesterol and fructosamine levels, but neither plasma triacylglycerol nor fasting glucose levels were reduced. Even after long periods (12 weeks) of a low-glycaemic-index diet, Brand et al. (1991) observed no change in plasma lipid levels, but glycosylated haemoglobin 
and mean plasma glucose levels were slightly decreased in type 2 diabetic patients. In these three studies the diet consisted of a mixture of several carbohydrates, whose glycaemic indexes were similar but not identical. The present study is particularly interesting because, in addition to allowing a better control of food intake, always difficult to achieve in clinical studies, it elicited significant differences in plasma triacylglycerol concentrations with two diets each containing one type of starch only. Thus, two starches of different botanic origin, which produce different postprandial plasma glucose and insulin responses, may, in the long term, have different effects on plasma lipid levels.

Glucose metabolism was also moderately improved but with different consequences in either normal or diabetic rats. Comparison of the two diets elicited a net improvement in fasting plasma glucose in normal but not in diabetic rats. Insulin levels tended to decrease after the mung-bean-starch diet. No significant reduction was found in the level of fructosamine. This could be due to lack of sensitivity of the test for detecting slight postprandial changes before the end of the nutritional period. Plasma glucose levels during the glucose tolerance tests were not influenced by the type of diet after 5 weeks. Jenkins $e t$ al. $(1987 a)$ observed similar results at the end of 2 weeks of a low-glycaemic-index diet. Thus, while a low-glycaemic-index diet produced a great modification in lipid metabolism in both normal and diabetic rats, it led to improvement of plasma glucose only in normal rats.

The exact mechanism by which a chronic low-glycaemic-index diet induced a decrease in fasting plasma glucose and lipid levels, particularly triacylglycerols, is still unknown. Albrink et al. (1979) suggested that these changes were secondary to a reduction in hepatic insulin-stimulated lipogenesis. Several studies have also implicated the high fibre content of low-glycaemic-index diets, but this hypothesis cannot be considered in our case where fibre content was kept constant. Consumption of high-amylose (compared with highamylopectin) diets for several weeks was found to induce lower post prandial plasma insulin and fasting plasma triacylglycerol levels in human subjects (Behall \& Howe, 1995). In our study, however, the slight difference in the amylose content between the two starches could not be implicated in the observed results. Another factor to be considered is the rate of intestinal starch digestion. There is strong evidence that the rate of starch hydrolysis (at $30 \mathrm{~min}$ in vitro) is a critical factor in determining the postprandial glycaemic responses to complex carbohydrates (O'Dea et al. 1981; Bornet et al. 1989). Our results in the present study again confirm this concept: after a single test meal high postprandial glycaemic responses to the wheat starch were accompanied by rapid in vitro $\alpha$-amylase hydrolysis. However, it may be questioned whether the different rates of digestion could have influenced, also, the chronic consequences in our study. This is unlikely, since the final body weight did not vary according to the type of starch digested. The content of resistant starch (starch escaping digestion in the small bowel) in the diet could also play an important role. Royall et al. (1990) observed that the percentage of resistant starch is inversely correlated with the glycaemic index of the diet. Some of the metabolic effects observed in the present study could indeed be explained by differences in short-chain fatty acids produced by the fermentation of resistant starch in the colon and their utilization by the liver.

We conclude that a 5 -week diet containing $570 \mathrm{~g}$ of a low-glycaemic-index starch $/ \mathrm{kg}$ compared with an isoenergetic isoglucidic high-glycaemic-index diet induced, in normal and diabetic rats: (1) a reduction in plasma lipid levels (triacylglycerols and phospholipids), (2) a decrease in epididymal adipocyte volume and (3) a tendency towards lower plasma insulin levels. In addition, the low-glycaemic-index diet decreased plasma glucose in normal, but not in diabetic rats.

Low-glycaemic-index starches could therefore contribute to improved lipid, and maybe long-term glucose, metabolism in type 2 diabetic patients. This type of diet may prove 
useful, also, in normal subjects, leading to a shift towards a less diabetogenic or atherogenic plasma profile.

We thank Prof. B. Guy-Grand for agreeing to measure plasma lipids in his laboratory, and Mrs M. Lavau for permitting us to make fat-cell-size measurements in her laboratory. This work was supported by grants from the National Institute of Health and Medical Research (INSERM) and from the Pierre and Marie Curie University.

\section{REFERENCES}

Albrink, M. J., Newman, T. \& Davidson, P. C. (1979). Effect of high and low fiber diets on plasma lipids and insulin. American Journal of Clinical Nutrition 32, 1486-1491.

Behall, K. M. \& Howe, J. C. (1995). Effect of long-term consumption of amylose vs amylopectin starch on metabolic variables in human subjects. American Journal of Clinical Nutrition 61, 334-340.

Bonner-Weir, S., Trent, D. F., Honey, R. N. \& Weir, G. C. (1981). Responses of neonatal rat islets to streptozotocin: limited B-cell regeneration and hyperglycemia. Diabetes 30, 64-69.

Bornet, F. R. J., Fontvieille, A. M., Rizkalla, S., Colonna, P., Blayo, A., Mercier, C. \& Slama, G. (1989). Insulin and glycemic responses in healthy humans to native starches processed in different ways: correlation with in vitro $\alpha$-amylase hydrolysis. American Journal of Clinical Nutrition 50, 315-323.

Brand, J. C., Colagiuri, S., Crossman, S., Allen, A., Roberts, D. C. K. \& Truswell, A. S. (1991). Low-glycemic index foods improve long-term glycemic control in NIDDM. Diabetes Care 14, 95-101.

Champ, M. (1992). Determination of resistant starch in foods and food products; interlaboratory study. European Journal of Clinical Nutrition 46, Suppl. 2, S51-S62.

Crapo, P. A., Reaven, G. \& Olefsky, J. (1977). Post-prandial plasma glucose and insulin responses to different complex carbohydrates. Diabetes 26, 1178-1183.

Dole, V. P. \& Meinertz, H. (1960). Microdetermination of long-chain fatty acids in plasma and tissues. Journal of Biological Chemistry 235, 2595-2599.

Englyst, H. N., Kingman, S. M. \& Cummings, J. H. (1992). Classification and measurement of nutritionally important starch fractions. European Journal of Clinical Nutrition 46, Suppl. 2, S33-S50.

Fontvieille, A. M., Acosta, M., Rizkalla, S. W., Bornet, F., David, P., Letanoux, M., Tchobroutsky, G. \& Slama, G. (1988a). A moderate switch from high to low glycaemic-index foods for 3 weeks improves the metabolic control of type 1 (IDDM) diabetic subjects. Diabetes Nutrition and Metabolism 1, 139-143.

Fontvieille, A. M., Bornet, F., Rizkalla, S. W., Le Francois, P., Pichard, P., Desplanque, N., Chevalier, A., Letanoux, M., Verel, A., Tchobroutsky, G. \& Slama, G. (1988 b). In vitro and in vivo digestibility and metabolic effects of 3 wheat-flour products (white bread, French toast (rusk) and French toast bran-enriched) in normal subjects. Diabète et Métabolisme 14, 92-96.

Fontvieille, A. M., Rizkalla, S. W., Penfornis, A., Acosta, M., Bornet, F. R. J. \& Slama, G. (1992). The use of low glycaemic index foods improves metabolic control of diabetic patients over five weeks. Diabetic Medicine 9, 1-7.

Goldrick, R. B. (1967). Morphological changes in adipocyte timing of fat deposition and mobilization. American Journal of Physiology 212, 777-782.

Jenkins, D. J. A., Wolever, T. M. S., Collier, G. C., Ocana, A., Rao, A. V., Buckley, G., Lam, L., Mayer, A. \& Thompson, L. U. (1987 a). Metabolic effects of a low-glycemic-index diet. American Journal of Clinical Nutrition 46, 968-975.

Jenkins, D. J. A., Wolever, T. M. S., Kalmusky, J., Guidici, S., Giordano, C., Patten, R., Wong, G. S., Bird, J. N., Hall, M., Buckley, G., Csima, A. \& Little, J. A. (1987 b). Low-glycemic index diet in hyperlipidemia: use of traditional starchy foods. American Journal of Clinical Nutrition 46, 66-71.

Jenkins, D. J. A., Wolever, T. M. S. \& Taylor, R. H. (1981). Glycemic index of foods: a physiological basis for carbohydrate exchange. American Journal of Clinical Nutrition 34, 362-366.

Lavau, M., Susini, C., Knittle, S., Blanchet-Hirst, S. \& Greenwood, M. R. C. (1977). A reliable photomicrographic method for determining fat cell size and number: application to dietary obesity. Proceedings of the Society for Experimental Biology and Medicine 156, 251-256.

Leclère, C., Champ, M., Cherbut, C. \& Delort-Laval, J. (1993). Starch digestion and amylase activity in the presence of guar gums. Science Alimentation 13, 325-332.

O'Dea, K., Snow, P. \& Nestel, P. (1981). Rate of starch hydrolysis in vitro as a predictor of metabolic responses to complex carbohydrate in vivo. American Journal of Clinical Nutrition 34, 1991-1993.

Portha, B., Blondel, O., Serradas, P., McEvoy, R., Giroix, M. H., Kergoat, M. \& Bailbe, D. (1989). The rat models of non-insulin dependent diabetes induced by neonatal streptozotocin. Diabète et Métabolisme 15 , 61-75.

Rodbell, M. (1964). Metabolism of isolated fat cells: effects of hormones on glucose metabolism and lipolysis. Journal of Biological Chemistry 239, 375-380.

Royall, D., Wolever, T. M. S. \& Jeejeebhoy, K. N. (1990). Clinical significance of colonic fermentation. American Journal of Gastroenterology 85, 1307-1312. 
Tollier, M. T. \& Robin, J. P. (1979). Adaptation de la méthode à l'arcinol sulfuric au dosage automatique des glucides neutres totaux condition d'application au extraits d'origine végétale (Adaptation of the sulphuric orcinol method to the automatic analysis of total neutral sugars: application to vegetable origin extracts). Annals de Technilogical Agriculture 28, 1-16.

Wolever, T. M. S., Jenkins, D. J. A., Jenkins, A. L. \& Josse, R. (1991). The glycemic index: methodology and clinical implications. American Journal of Clinical Nutrition 54, 846-854.

Wolever, T. M. S., Jenkins, D. J. A., Vuksan, V., Jenkins, A. L., Buckley, G. C., Wong, G. C. \& Josse, R. G. (1992). Beneficial effect of a low glycaemic index diet in type 2 diabetes. Diabetic Medicine 9, 451-458. 